\title{
RESULTS AFTER THE IMPLEMENTATION OF A PREOPERATIVE ANEMIA CORRECTION PROTOCOL IN ELECTIVE COLORECTAL SURGERY WITH AN "ERAS" PROTOCOL: A PROSPECTIVE COHORT STUDY
}

M. Cabellos Olivares, V. Jiménez Guitián, M. Labalde Martínez, M. Torralba, B. Amorós Alfonso, J. R. Rodriguez Fraile

\section{BACKGROUND AND GOAL OF STUDY}

Preoperative anaemia is associated with an increase in perioperative mortality. Enhanced recovery after surgery (ERAS) protocols recommend the detection of anaemia to reach a preoperative hemoglobin within the margins of normality defined by the World Health Organization (WHO) (men $\geq 13 \mathrm{~g} / \mathrm{dl}$; women $\geq 12 \mathrm{~g} / \mathrm{dl}$ ).

\section{MATERIALS AND METHODS}

A total of 256 patients were included. We compared the first 121 consecutive patients that participated in the ERAS (from May 2016 to January 2017) with 135 consecutive patients that were operated prior to implementation of the program (from January to December 2015). The main variables of the study were preoperative hemoglobin, number of patients transfused and number of red blood cell transfusions during the hospital stay.

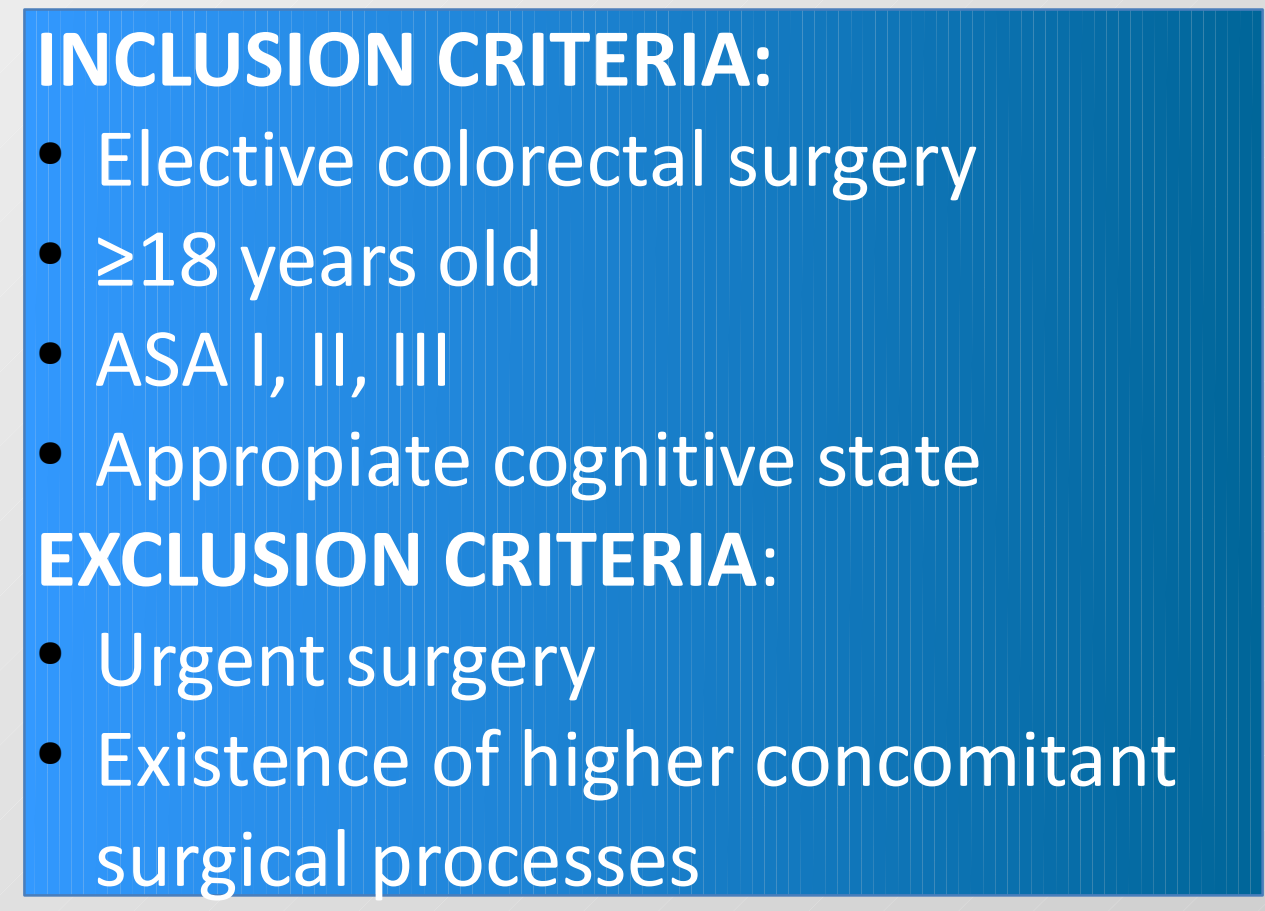

\section{RESULTS}

Table 1: Main characteristics of both groups

\begin{tabular}{|l|c|c|c|} 
& Pre-ERAS(n 135) & ERAS $(n+121)$ & $p$ \\
\hline Age & $68.43 \pm 12.26$ & $68.43 \pm 13.38$ & 0.169 \\
\hline Men & $41(30.4 \%)$ & $44(36.7 \%)$ & 0.309 \\
\hline Women & $94(69.7 \%)$ & $77(63.6 \%)$ & \\
\hline ASA 1 & $10(7.4 \%)$ & $12(9.9 \%)$ & 0.417 \\
ASA 2 & $86(64.7 \%)$ & $66(54.6 \%)$ & \\
\hline ASA 3 & $39(28.9 \%)$ & $43(35.5 \%)$ & \\
\hline
\end{tabular}

Diagnosis

- Colorrectal cancer

- Others

$116(85.93 \%)$

$19(14.07 \%)$

$109(90.08 \%)$

$12(9.92 \%)$

\begin{tabular}{|l|c|c|}
\hline Laparoscopy & $27(20 \%)$ & $45(37.2 \%)$ \\
\hline Open surgery & $108(80 \%)$ & $76(62.8 \%)$ \\
\hline
\end{tabular}

\begin{tabular}{|l|l|l|}
\hline Preoperative haemoglobine & $13.3(8.6-16.6)$ & $12.98(8.5-16.7)$ \\
\hline
\end{tabular}

0.732

\begin{tabular}{|c|c|c|c|}
\hline Number of & patients & 31 (22.96\%) & 15 (12.4\%) \\
\hline
\end{tabular}

transfused

Number of red blood cell

$3 \pm 1.57$

$1.8 \pm 0.56$

$<0.001$

Tables $1 \& 2$

Table 2: application of the preoperative anaemia correction protocol

$\begin{array}{llll}\begin{array}{l}\text { Patients who received iron in the } \\ \text { preoperative period }\end{array} & \text { Pre-ERAS } & \text { ERAS } & p \\ \text { Oral iron } & 21(15.6 \%) & 16(13.2 \%) & 0.722 \\ \text { EV iron } & 3(2.23 \%) & 31(25.6 \%) & <0.001 \\ \text { Erythropoietin } & 0 & 2(1.6 \%) & \end{array}$

\section{CONCLUSION}

The application of a pre-operative anaemia optimization protocol in patients undergoing elective colorectal surgery according to ERAS guide allowed a reduction in the number of red blood cell transfusions and in the total number of patients transfused. 